Сидоров А. И., Евстигнеев А. И.

A. I. Sidorov, A. I. Yevstigneyev

ОБ ОДНОМ СПОСОБЕ ЕСТЕСТВЕННОЙ ОЧИСТКИ ВОДЫ ЗА СЧЁТ ПРИЛИВОВ И ОТЛИВОВ МОРЯ

\title{
ON ONE METHOD OF NATURAL WATER PURIFICATION AT THE EXPENSE OF TIDES AND EBBS OF THE SEA
}

Евстигнеев Алексей Иванович - доктор технических наук, профессор, советник при ректорате Комсомольского-на-Амуре государственного университета (Россия, Комсомольск-на-Амуре). E-mail: diss@knastu.ru.

Mr. Alexey I. Yevstigneyev - Doctor of Engineering, Professor, university Administration Adviser for Research, Komsomolsk-on-Amur State University (Russia, Komsomolsk-on-Amur). E-mail: diss@knastu.ru.

Сидоров Алексей Иванович - научный сотрудник Комсомольского-на-Амуре государственного университета (инженер) (Россия, Комсомольск-на-амуре). E-mail: natasi 79.79@mail.ru.

Mr. Alexey I. Sidorov - researcher of Komsomolsk-on-Amur State University (engineer) (Russia, Komsomolskon-Amur). E-mail: natasi79.79@mail.ru.

Аннотация. В статье представлен новый экономичный способ естественной очистки воды в прибрежной морской зоне с помощью энергии приливов и отливов; разработана конструкция опытной установки по реализации способа.

Summary. A new economical method of natural water purification in the coastal marine zone due to tidal energy has been introduced; the design of the pilot plant for the implementation of the method has been developed.

Ключевые слова: естественная очистка воды, аквапарки, прилив, отлив, прибрежная зона моря.

Key words: natural water purification, water parks, tide, reflux, coastal zone of the sea.

УДК 627.8 .03

Одной из нерешённых проблем является проблема естественной очистки воды в аквапарках, бассейнах, спортивно-оздоровительных комплексах, расположенных на берегу моря и (или) в прибрежной зоне.

Известен способ очистки воды [1], при котором вода очищается путём принудительной подачи чистой воды в нижнюю часть чаши и естественного слива загрязнённой воды из верхней части чаши. Эта операция выполняется посредством узла ввода, состоящего из блока забора воды, насосной станции с электронасосами, трубопровода с задвижкой подачи воды в чашу и выходной системы подачи чистой воды, расположенной на дне или по периметру дна чаши. Операция способа естественного слива верхних загрязнённых слоёв воды из чаши, выполняемая благодаря её расположению выше уровня моря, реализуется посредством узла вывода, состоящего из системы сбора верхних слоёв воды и трубопровода с задвижкой слива верхних слоёв воды. Такая система может быть выполнена, например, в виде переливной кромки по периметру верхней части чаши. Этот высокоэффективный способ нашёл широкое применение в аквапарках, бассейнах, спортивнооздоровительных комплексах. Но это сопровождается большими затратами на электроэнергию, связанными с принудительной подачей больших объёмов воды электронасосами.

Известен способ очистки воды [2], включающий в себя две операции: принудительную подачу чистой воды в нижние слои чаши и естественный слив верхних загрязнённых слоёв воды из чаши. Операция принудительной подачи воды выполняется посредством узла ввода, в состав которого входит блок забора воды, насосная станция с электронасосами, трубопровод с задвижкой подачи воды в чашу и выходная система подачи чистой воды, расположенная на дне или по периметру дна чаши. Операция естественного слива верхних загрязнённых слоёв воды из чаши выполняется посредством узла вывода, в состав которого входит система сбора верхних слоёв воды 


\section{Учёнье записки \\ Комсомольского-на-Амуре государственного технического университета \\ 2019}

и трубопровод с задвижкой слива верхних слоёв воды. В целом этот способ приобретает искусственный (принудительный) характер очистки воды и требует значительных затрат на электроэнергию в связи с подачей больших объёмов воды электронасосами, на проектирование и установку для каждого объекта специальной системы подачи воды, учитывающей гидродинамические ударные нагрузки при пуске электронасосов.

Задачей нового решения [3] является упрощение системы подачи воды и снижение эксплуатационных затрат вследствие использования приливов и отливов моря для естественной очистки воды. Решение задачи заключается в упрощении системы подачи воды и устранении затрат на электроэнергию благодаря замене искусственной подачи и очистки воды посредством насосной станции на естественную за счёт приливов и отливов моря.

Упрощение системы подачи воды достигается не только из-за высвобождения дорогостоящей насосной станции с электронасосами, но и вследствие устранения гидродинамических ударных нагрузок при пуске электронасосов. Статические плавно меняющиеся безударные нагрузки приливов позволяют вместо металлических конструкций в системе подачи морской воды применить некоррозийные пластмассовые. Так как верхний уровень воды в чаше не выше уровня моря после прилива, а узел вывода воды расположен ниже уровня воды в чаше, трубопровод узла ввода воды с блоком забора воды с нижних слоёв моря укладывается по дну моря на достаточно удалённом расстоянии от берега, например, 200 метров и более в зависимости от экологического состояния моря, благодаря чему и решается эта задача. Дополнительный результат достигается за счёт того, что при работе аквапарков, бассейнов, спортивно-оздоровительных комплексов круглосуточное обновление (очистка) воды производится утром на предзавершающей стадии прилива, когда уровень воды в чаше выше уровня моря. Предлагаемый авторами способ [3] включает в себя две операции: ежедневный естественный слив верхних загрязнённых слоёв воды из чаши во время морского отлива и естественное пополнение чаши чистой водой во время морского прилива. Операция естественного слива верхних загрязнённых слоёв воды из чаши во время морского отлива выполняется посредством узла вывода, состоящего из блока забора воды, трубопровода с задвижкой подачи воды в чашу и выходной системы подачи чистой воды, расположенной на дне чаши.

Этот способ отражён на рис. 1.

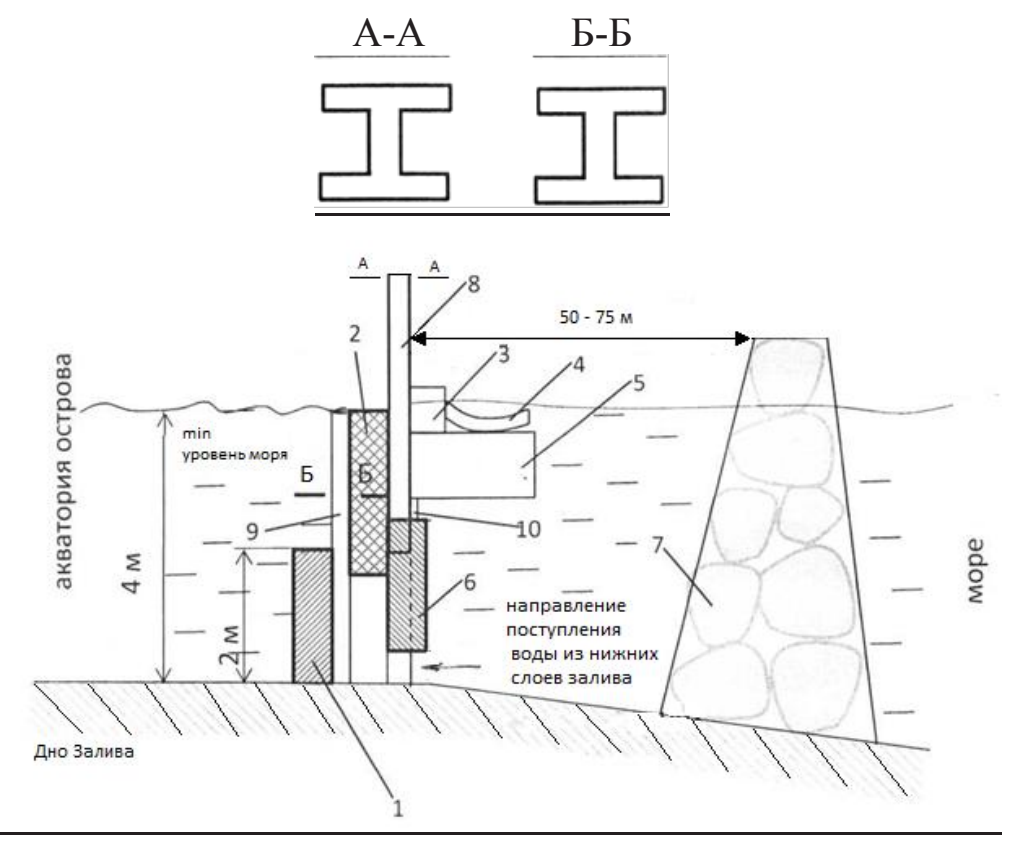

1 - кассетный джутовый фильтр; 2 - защитная стенка; 3 - верхняя шиберная затворка;

4 - конвейерная сетка; 5 - понтон; 6 - нижняя шиберная затворка; 7 - волнолом;

8 - направляющая понтона и нижней заслонки; 9 - направляющая для монтажа фильтра;

10 - соединение понтона с нижней шиберной заслонкой

Рис. 1. Схема конструкции по очистке воды за счёт морских приливов и отливов 
Сидоров А. И., Евстигнеев А. И.

ОБ ОДНОМ СПОСОБЕ ЕСТЕСТВЕННОЙ ОЧИСТКИ ВОДЫ ЗА СЧЁТ ПРИЛИВОВ И ОТЛИВОВ МОРЯ

Каждые сутки ночью или рано утром во время морского отлива открывают задвижку слива верхних слоёв воды через трубопровод узла вывода. После частичного слива воды из чаши задвижку слива верхних слоёв воды закрывают и затем на период прилива моря (или на весь день до начала отлива) открывают задвижку подачи воды в чашу через узел ввода, состоящего из блока забора чистой воды с нижних слоёв моря, трубопровода и выходной системы подачи чистой воды, расположенной на дне чаши или по периметру дна.

\section{ЛИТЕРАТУРА}

1. Патент РФ № 2424200, МПК ЕОЗВ 1/00, Е02B 15/00, B01D 35/06, С02F 1/36, F25D 2/00. Система очистки и обеззараживания воды в плавательных бассейнах / Боев В. Ф., Улановский Я. Б., Рудых Г. С.; патентообладатель ООО «Стройинжиниринг СМ» (RU). - № 2009129257/05; заявл. 30.07.2009; опубл. 20.07.2011. Бюл. № 20.

2. Патент РФ №79582, МПК ЕОЗВ 1/00, Е02B 15/00, B01D 35/06, C02F 1/36, F25D 2/00. Технический водный комплекс / Плугин А. И., Манюк Е. Л., Крылов Н. Н.; патентообладатель Плугин А. И. № 2008137576/22; заявл. 19.09.2008; опубл. 10.01.2009. Бюл. № 1.

3. Патент № 2547929, МПК Е 02В 15/00, ЕОЗВ 1/00. Способ естественной очистки воды за счёт приливов и отливов моря в аквапарках, бассейнах, спортивно-оздоровительных комплексах, расположенных на берегу и (или) в прибрежной зоне / А. И. Сидоров, А. И. Евстигнеев, В. С. Климаш. - № 2013153429; заявл. 02.12.2013; опубл. 10.04.2015. 